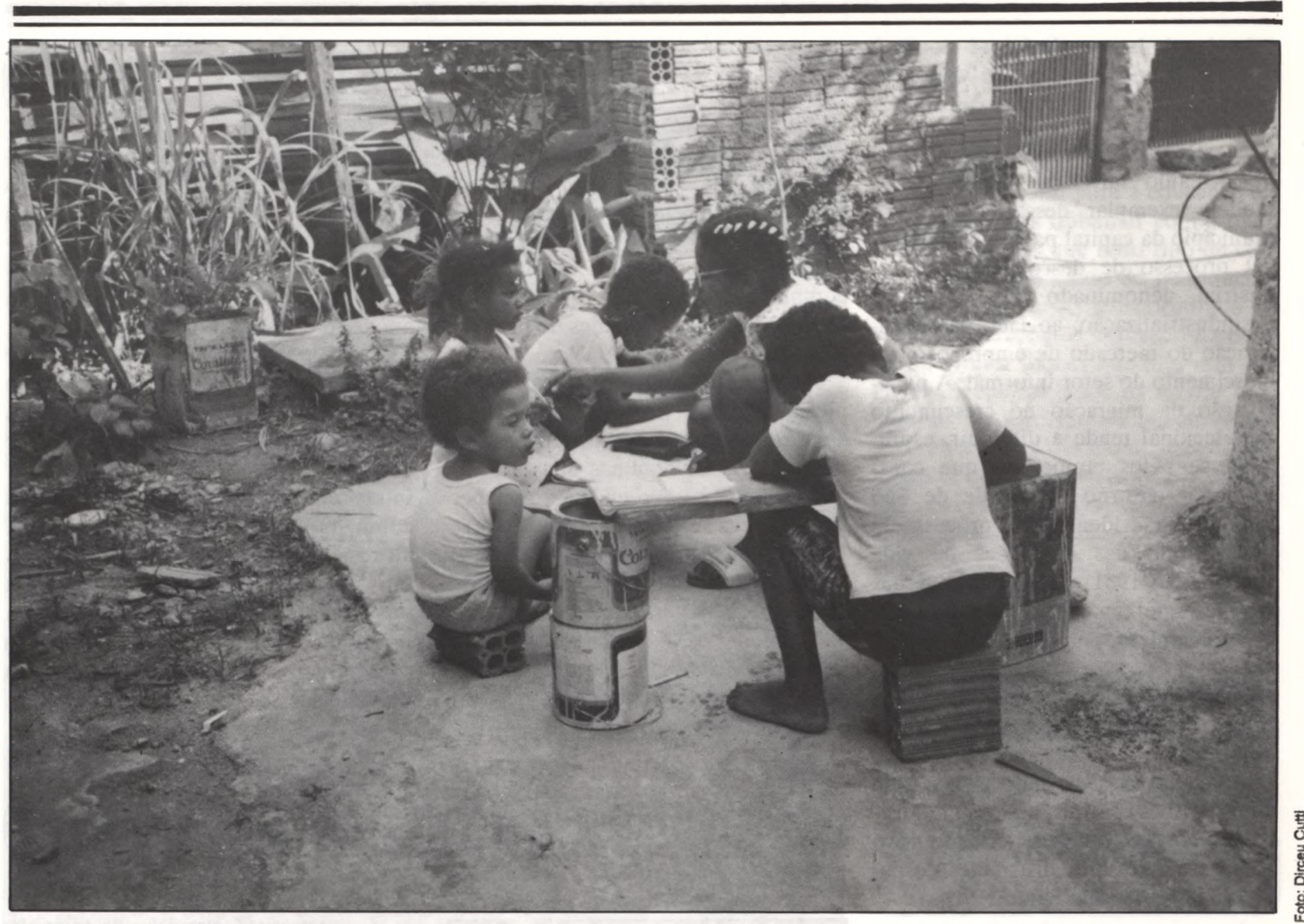

\title{
INDAGAÇÕES SOBRE A EDUCAÇÃO DE JOVENS FILHOS DE MIGRANTES
}

\section{Marilia Pontes Sposito*}

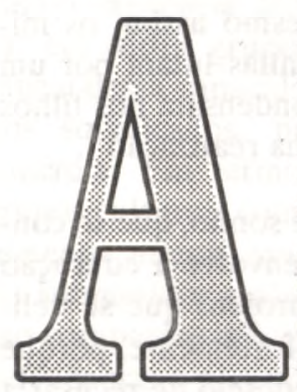

década de 90 confirma, para muitos, a sensação de impasse e de falta de perspectivas para a sociedade brasileira. A recessão que marcou a última década, agravada pela profunda crise que ultrapassa as fronteiras da miséria social, atingindo as instituiçôes e comprometendo o processo de transição democrática, é a grande herança para os próximos anos. Tais efeitos são imediatamente perceptíveis sob o ponto de vista geral da sociedade e de seus segmentos explora- dos. No entanto, seria preciso aprofundar o quanto esta situação de crise atinge particularmente os jovens, filhos de trabalhadores migrantes 1 .

Sob o ponto de vista mais geral, as estatísticas tendem a confirmar que há um "envelhecimento populacional" na medida que a presença da faixa etária dos 0 aos 19 anos tende a diminuir, ainda que discretamente nos últimos anos, no conjunto da população brasileira ${ }^{2}$.

Este envelhecimento populacional cria novos desafios e alguns paradoxos, uma vez que, de modo inegável, a questão do idoso configura-se como importante sob o ponto de vista das políticas públicas. Mas tal processo ocorre ao lado de problemas crônicos e de omissões do Estado no que se refere às políticas para a juventude e infância, quer sob o ponto de vista das possibilidades educacionais, como sob a ótica do mercado de trabalho e do lazer. Este quadro tende a se agravar porque a distribuição das faixas etárias incide de modo diferente de acordo com a renda aferida. Assim, a população jovem tende a se concentrar nos segmentos mais pauperizados da população, aqueles que cotidianamente ressentem-se da ausência das políticas públicas na área social e sofrem os efeitos da crise econômica e da recessão. 


\section{SÃO PAULO: UM EXEMPLO PERVERSO}

A Região Metropolitana de São Paulo talvez se constitua em modelo exemplar dessa situação. $\mathrm{O}$ município da capital passa por um visível processo de desconcentração industrial, denominado por alguns de desindustrialização, ao lado da terciarização do mercado de empregos e do crescimento do setor informal. A participação da migração no crescimento populacional tende a diminuir, espraiando-se pelos municípios que constituem o entorno da cidade de São Paulo. Nela, evidencia-se o processo de deterioração das condições de vida pois, se em 1981 cerca de 34,7\% đas famílias aferiam renda de até um salário mínimo, em 1987 estes índices chegam a $42,1 \%$. Se considerarmos apenas sob o ponto de vista do espaço urbano, é possível verificar que a população de 0 a 19 anos está concentrada nas áreas periféricas da cidade e nos bolsões centrais, onde estão localizados cortiços e favelas, criando novo patamar perverso de distribuição espacial da pobreza (São Paulo:1990).

A concentração e fixação das famílias migrantes ocorrem nessas regiões, embora grande parte das levas migratórias tenda hoje a se alocar nos municípios que constituem a Região Metropolitana, dadas as difíceis condições de moradia na capital.

Integrantes de família migrante, lutando para sobreviver diante dos desafios do dia-a-dia, residentes nos bairros periféricos ou buscando moradia nas áreas centrais em cortiços ou favelas, crianças e jovens enfrentam as deficiências da rede pública de educação.

Os serviços educacionais não conseguem absorver a demanda de vagas, revelando uma extrema desigualdade espacial na capacidade de atendimento, pois nos bairros pobres e periféricos a oferta ainda é deficitária, as escolas estão superlotadas, havendo déficit de construções e o recurso a soluções improvisadas para absorver novas matrículas ${ }^{3}$.

Aos problemas crônicos de atendimento somam-se os altos índices de exclusão e repetência, invalidando, na prática, a luta cotidiana de vários grupos populares pela conquista do direito à educação mediante pressões e movimentos organizados pela expansão dos equipamentos públicos escolares: creches, pré-escolas, unidades de primeiro e segundo graus ${ }^{4}$.

No entanto, para se resgatar a complexidade desses processos, é preciso ir além do quadro descrito pelas estatísticas e levantar algumas questões que possibilitem compreender a perspectiva dos seus sujeitos. Marcados por reflexões demasiadamente abstratas ou de corte estruturalista, os estudos sobre educação recuperaram, nos últimos anos, apenas as determinações de classe, negligenciando as múltiplas formas que reproduzem as dimensões da do- minação e da opressão. Somente a partir de meados da década de 80 , outras categorias começam a incorporar a análise, recuperando questões centrais como as de gênero e aquelas que envolvem grupos geracionais, sobretudo a análise da criança, do jovem e do idoso.

Neste artigo privilegiamos o ponto de vista dos jovens, não eliminando a importância de se considerar a criança como sujeito de processos sociais que vivencia, sendo capaz de produzir interpretações (Martins:1991). Tendo como ponto de partida os jovens, atores de processos sociais dos quais são vítimas e protagonistas, busca-se oferecer alguns indícios que apontem os desencontros que se abrem frente a seus projetos de vida e à educação a que têm acesso.

\section{MIGRAR E EDUCAR PARA O FUTURO}

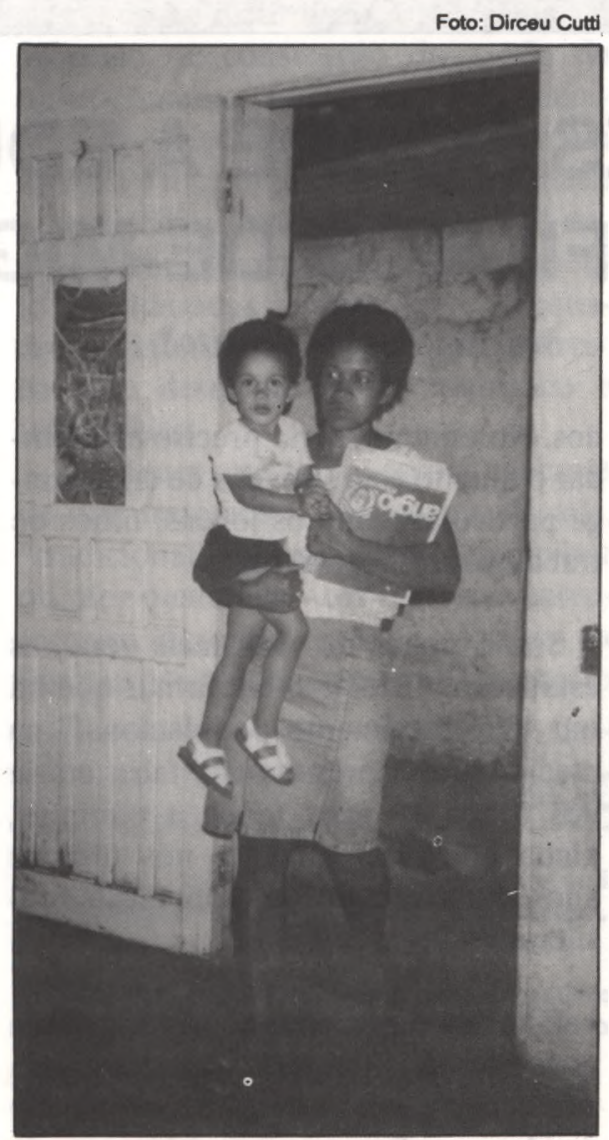

A migração é expulsão da terra de origem e, ao mesmo tempo, busca de novos caminhos. Enquanto busca acalenta projetos, sonhos e esperanças. É verdade que o agravamento das condições de vida no campo e a hostilidade da cidade têm deteriorado o conteúdo do sonho e do projeto, talvez negando não só o direito de ser mas o de vir a ser, consubstanciado em uma idéia de futuro. Mesmo assim, os migrantes em suas famílas lutam por um destino melhor e condensam nos filhos a possibilidade de sua realização ${ }^{5}$.

O conteúdo desse sonho, que se configura em projeto, envolve a educação dos filhos. É um projeto que se delineia imprecisa mas fortemente, porque nele está contido o desejo de recusar a condição de vida que lhe foi imposta, lutando por um futuro melhor, mediante a vontade de um outro destino para o filho. É preciso oferecer aos filhos o que não se teve: a escola. Mas essa educação desejada não integrou a experiência concreta de sua existência 


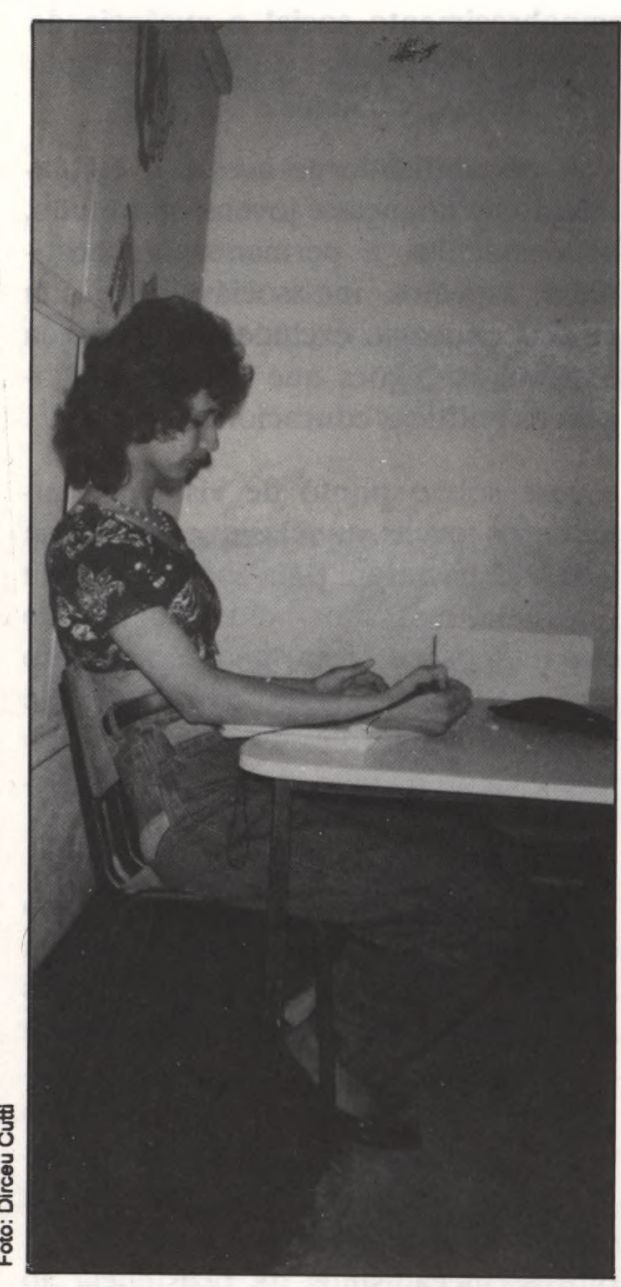

anterior, porque as condições de vida recusaram a escola, ela não foi incorporada em sua trajetória e, assim, aparece como sonho, utopia e, muitas vezes, como mito. Além de uma ocupação mais digna, a escola pode oferecer o saber para a sobrevivência. Os filhos precisam ser "sabidos", donos de um saber que permita enfrentar não apenas a pobreza, mas as várias dimensões da subalternidade: a opressão, a dominação e a humilhação.

A densidade e importância do projeto, ainda que mal delineado em seus contornos, são medidas pela luta cotidiana pela sobrevivência e para oferecer "condições de estudo para os meninos"; desdobram-se nos inúmeros movimentos e lutas radicados nas periferias, nos últimos anos, onde a educação sempre foi questão importante. Enfim, casa, saúde e educação constituem uma trilogia inseparável, um elemento alimentando o outro e tećendo os fios da vida e da utopia.

\section{OS DESENCONTROS ENTRE PROJETOS: COMO ESTÃO OS JOVENS?}

Como estão os filhos diante dos tam? projetos que seus pais acalen-

Para as novas gerações, socializadas na cidade grande, o início da vida escolar é recoberto de muitos significados: "ir à escola é como ser batizado e fazer primeira comunhão, deve-se cumprir o estabelecido e pronto"6

No conteúdo das lembranças daqueles que hoje são jovens, a interiorização do mundo social com suas regras e valores mediatizados pela família apresenta o caráter inquestionável do bem que é a ida à escola. Tão sagrado como as práticas religiosas, $\mathrm{o}$ acesso a escola também adquire as características da ritualização: é preciso ir, muito embora não se entenda, de início, o porquê de tanta importância, de tanto valor.

Os desencontros se iniciam precocemente, pois as práticas escolares, as exigências de material escolar e de recursos na casa para apoiar as tarefas diárias não podem ser respondidas pela família e transformam a permanência na escola em desafio ou teimosia, muitas vezes traduzidos mais pelo desejo dos pais do que pela curiosidade ou o interesse infantis.

Mas a vida provoca outras rupturas, novos desencontros e a necessidade do trabalho aparece em poucos anos ${ }^{7}$. Se este é um aspecto que determina fortemente o abandono da escola ou o início da dupla jornada, escola noturna e trabalho, é preciso considerar que nos bairros periféricos, muitas vezes, o próprio sistema escolar facilita a ida de crianças e jovens para o mundo das ocupações. As características internas ao processo educativo muitas vezes excluem crianças e jovens que, após esse primeiro desencanto, buscam no trabalho uma alternativa de vida, ainda que provisória. Em outras situações, a incapacidade de atendimento das escolas no período diurno empurra para as classes noturnas as séries mais adiantadas, independentemente da idade ou necessidade dos alunos. Assim, estudando só à noite, esses jovens são levados a buscar qualquer emprego ou bico, muitas vezes estimulados pela própria família, diante das preocupações advindas do número excessivo de horas "de ócio" e "de rua" para aqueles que não assumem os encargos domésticos diante da labuta diária dos pais, que permanecem muitas horas ausentes de casa.

Os desencontros se acentuam, provocando as idas e vindas, dando um caráter intermitente tanto ao mundo do trabalho como ao mundo da escola (Madeira:1986). Esta descontinuidade, no entanto, revela de modo mais profundo o desencontro das temporalidades: o tempo da escola e o tempo da vida. Projetado linearmente, o tempo da escola não permite o seu fracionamento. A ruptura e cada interrupção sempre são vividas como perdas, algumas delas irreparáveis.

Na multiplicidade dos tempos, o tempo linear da reprodução mercantil do trabalho também é vivenciado cotidianamente em meio à percepção de novas exigências. No mercado de compra e venda da força de trabalho este jovem percebe os efeitos mais visíveis da exploração consubstanciada na desigualdade dos salários. Ao vender sua força de trabalho ele luta pela sua valorização. A desigualdade com que convive é expressa pela comparação que realiza frente aos outros trabalhadores que podem receber maiores salários e pelo grau crescente de exigências que os empregadores fazem para a obtenção de qualquer cargo, sobretudo a elevação dos requisitos escolares. E novamente a escola aparece como forma de resposta individual à đepreciação que ele sofre no mercado.

Os caminhos são variados: após alguns anos de escola básica, o abandono. Muitas vezes os cursos rápidos oferecidos pelo SENAI, SENAC ou grupos privados são alternativas. Para alguns há o retorno à escola pública, muitas vezes para o Curso Supletivo, 
procurando concluir o primeiro grau ou o segundo grau noturno para os que já conseguiram vencer as barreiras iniciais.

Os jovens que terminaram o segundo grau, uma minoria, percebem o valor meramente credencialista da escola: “o que vale é o papel, então o pessoal cobra muito se a gente é diplomado ou não, tem o negócio do diploma, eles estão sempre te avaliando pelo papel, não importa se na escola que a gente esteve a gente aprendeu as coisas pela metade ou se não foi um negócio forçado ou se não era nada daquilo da realidade da gente".

O agravamento das condições de vida nos últimos anos tende a descortinar um horizonte mais complexo no mundo do trabalho.

A relativa autonomia dada pelo salário permite realizar apenas parte do consumo próprio de jovens como discos, roupas, jeans, tênis, o som, "ostentando marcas visíveis de pertencimento à categoria jovem, sobretudo aquelas veiculadas pelos meios de comunicação" (Madeira:1986). Mas este processo criou o descompasso entre as pressões e necessidades de consumo, que são impostas socialmente, e as escassas possibilidades de realização. Os desencontros entre o padrão de consumo real e as expectativas engendradas são potencialmente geradores de conflitos, não só no âmbițo familiar como do ponto de vista social mais amplo.

De outra parte, jovens migrantes socializados na ética do trabalho e para o trabalho, cujo modelo está inscrito na luta diária dos pais, não encontram nesse mundo das ocupações, alternativas e possibilidades de ascensão. Sequer ohservam na trajetória familiar os frutos advindos do esforço e da labuta diária no trabalho. O país está mais pobre, as famílias se empobreceram e as perspectivas de melhoria estão cada vez mais reduzidas. A pobreza crescente caminha ao lado de um amplo apelo ao consumo de bens materiais e simbólicos. A erosão das instituições, sua perda da legitimidade, as escassas possibilidades para as novas gerações também corroem a ética e os projetos incorporados no âmbito da família.

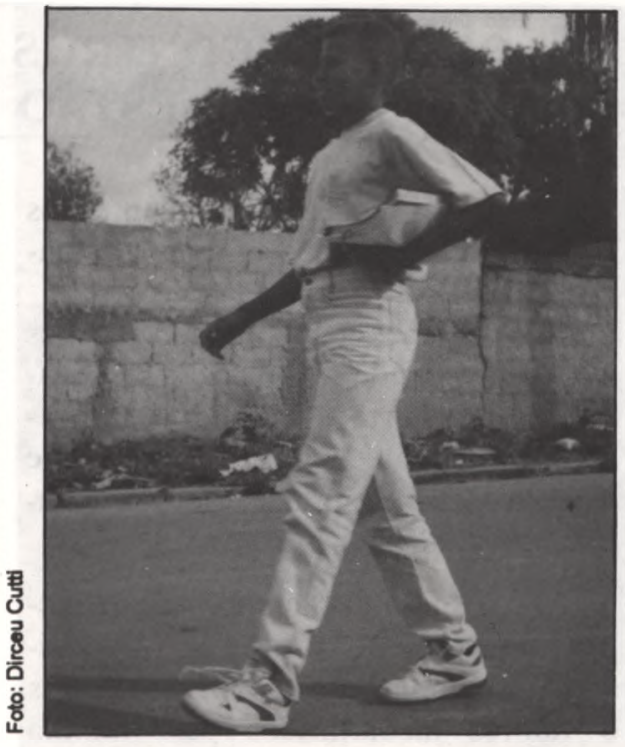

Como jovem ele vive a dimensão da transitoriedade, ele está em movimento para algo diverso, busca realizar um projeto para o seu futuro (Braslavsky: 1985 e Mannheim: 1954). O conteúdo de tais projetos é múltiplo e, em grande parte, desconhecido por educadores e familiares.

Mas é preciso acrescentar a liminaridade como outro elemento para enriquecer a compreensão dessa condição. A relativa autonomia do jovem frente à família, a vontade de marcar fronteiras próprias que o identifiquem, possibilitam seu distanciamento e o tornam mais distante das exigências do mundo adulto, afastando-o do mundo infantil. Tanto a transitoriedade como o estranhamento contêm a idéia de que os jovens vivem cotidianamente no limiar: entre um código de regras e outro; entre os projetos familiares, a escola e o mundo da rua com a turma e os grupos espontâneos. Tais alternativas nem sempre redundam em escolhas compatíveis com as formas e expectativas dominantes, mas podem conter um nova legitimidade e novos projetos para a vida social.

\section{EM BUSCA DE UM NOVO PROJETO EDUCATIVO}

A escola pública vive momentos de crise e desafios que não podem ser reduzidos apenas à situação de empobrecimento social e ausência de políticas consistentes do Estado diante da ofensiva neoliberal.

A possibilidade de acesso à escolarização de crianças e jovens, sobretudo, os obstáculos à permanência constituem aspectos indissociáveis de um mesmo processo excludente que ainda demanda soluções que não se restringem às políticas educacionais.

Mas sob o ponto de vista dos sujeitos, os jovens, aqueles que de alguma forma já passaram pela escola ou a ela retornam, marcados pelo antagonismo dos tempos - a linearidade do projeto escolar, a linearidade do processo de trabalho mercantilizado frente aos ritmos e ciclos da vida cotidiana - as insatisfações são mais fundas.

Embora anteveja a importância do conhecimento sistematizado, o jovem apreende do processo educativo mais suas funções credencialistas do que a possibilidade de apropriação de instrumentos para conhecer e decifrar o mundo em que vive. Atenua suas expectativas de ascensão individual e a escola aparece como mais um, entre outros, mecanismos de resistência ao processo de desvalorização da força de trabalho: é preciso ir à escola para sobreviver, embora, muitas vezes, prevaleça a sensação "de ser carta fora do baralho".

$\mathrm{E}$, assim, em um aparente movimento contraditório, o jovem rejeita aquilo que o conhecimento pode lhe oferecer, uma vez que o modo de transmissão e as estratégias vigentes no sistema de ensino, somados às características do mercado de trabalho, produzem efeitos contrários àqueles inicialmente pretendidos pelos educadores.

Suas necessidades são mais amplas, os jovens buscam na escola, muitas vezes sem encontrar, um espaço de sociabilidade e de troca de experiências que ultrapassa as dimensões do processo instrucional. Sua trajetória é multifacetada, pois a transitoriedade envolve projetos e caminhos diversos: a vida pessoal, o lazer, a sexualidade, conflitos e perspectivas de vida em família, alter- 
nativas para a participação e presença na vida pública. No entanto, essas questões têm sido objeto de desatenção e, muitas vezes, não estão presentes na construção de novas alternativas pedagógicas. Seria possível um novo projeto pedagógico sem assumir como pressuposto a dupla condição de jovem e trabalhador que exige um tratamento. diverso? Não seria necessário admitir, como ponto de partida, que é preciso. realmente conhecê-lo, decifrar suas angústias e sonhos?

Por essas razões, a possibilidade de novos projetos educativos para a juventude, sobretudo para os filhos de trabalhadores migrantes, não deve excluir o que aparentemente já está fora do alcance do domínio pedagógico. Não se torna mais possível, hoje, ignorar dentre outras questões, o problema da violência, sobretudo aquela que atinge diretamente os jovens dos bairros periféricos e oriundos da classe trabalhadora $^{8}$.

Sem adentrar nos processos mais gerais da violência e da exclusão social, é preciso, no entanto, ressaltar o modo como a própria escola tem sido alvo da violência, empreendida, sobretudo, por jovens e crianças. Escolas são depredadas e agredidas, envolvendo muitas vezes professores, funcionários e alunos. No dia-a-dia da atividade escolar, estas questões têm sido predominantemente tratadas como problemas de segurança e, portanto, como parte de um outro mundo, o dos "marginais", que não afeta ou atinge a vida escolar. A escola, em grande parte, têm excluído, por processos diversos, jovens e crianças já vitimados pela exclusão social, que se transformam em agressores e deixam de integrar a "comunidade escolar”. A condição de liminaridade da juventude produz um conjunto de transgressões diárias que, em geral, produzem interpretações sobre suas ações que captam apenas os seus aspectos mais evidentes. Carregadas de estereótipos, estas interpretações tendem, cada vez mais, a estigmatizar, isolando a escola do mundo da rua e da vida.

Mas a violência que atinge hoje a escola pública pode ser analisada a partir de outros parâmetros. Ela encerra várias modalidades de protesto e resposta frente às formas de agressão impostas pelo sistema educativo e o Estado. Esta violência encerra uma modalidade de recusa desta escola que está sendo oferecida e que, gradativamente, perde sentido para parcelas cada vez mais significativas de jovens e crianças.

Embora a recusa desta escola possa estar recoberta por uma aparente negação da educação escolar em geral, este é apenas o aspecto mais visível do processo. É indiscutível que um alvo tão privilegiado para a agressão, mais atingido do que outros equipamentos públicos e sociais, continue de algum modo sendo importante nos projetos negados e recusados aos jovens, hoje. No aparente caos e na crise vigente, podem estar sendo gestados uma nova legitimidade, o esboço de outras alternativis e de um novo projeto educativo.

Repensar a possibilidade da educação para jovens filhos de migrantes em meio à crise descortinada para os anos 90 é tarefa complexa e desafio estimulante. Mas os momentos de crise são, também,portadores do novo. Podem introduzir legitimidades alternativas e produzir uma nova sociabilidade. Neste esforço, que é sobretudo coletivo, talvez se possa resgatar os sonhos acalentados pela geração dos pais migrantes e oferecer condições para que os jovens sejam portadores de uma nova utopia.

* Marilia P. Sposito é professora da Faculdade de Educação da USP.

\section{NOTAS}

1. Neste artigo a designaçáo jovem compreende a faixa etáría dos 15 aos 24 anos, sem que essa abrangência signifique critério estatistico e exclua, em situaçôes concretas, o grupo de crianças com mais de 10 que, em funçăo de suas condiçóes de vida, inicia prococemente sua inserção no mercado de trabalho.

2. Em $1960,52,84 \%$ da populaçâo brasileira eram constituídos por grupos etários com menos de 20 anos. Ja em 1985 reduz-se essa presença para 46,98\% (Fundaçăo Seade: 1988)

3. Em bairros pobres da cidade de Săo Paulo, como Capela do Socorro, S. Mateus, V. Jaguara, V. Brasilándia e Sapopemba, entre $35 \%$ e $40 \%$ da população da faixa etária de 7 a 14 anos não têm acesso à escolaridade básica (Mello: 1991)

4. No município de São Paulo, $32 \%$ dos jovens de 10 a 17 anos já compunham, em 1985, a População Economicamente Ativa (Mello: 1991)

5. Este tema foi desenvolvido no artigo O Migrante e a Educaf̧ấo: o sonho nutre a luta, TRAVESSIA, Ano I, $\mathrm{n}^{\circ} 02$, Dezembro, 1988.

6. Os depoimentos, citados entre aspas, são de grupos de jovens, filhos de migrantes e moradores da Zona Leste da cidade de São Paulo. Em meados dos anos 80, integravam o Movimento de Educação da Zona Leste, que lutou pela ampliação da rede pública de segundo grau e de cursos supletivos.

7. A População Economicamente Ativa Urbana no Brasil, nos anos de 1970 e 1980 , sofreu processo de rejuvenescimento. Verifica-se que na faixa de 10 14 anos os índices saltam de 1,8\% para $2,6 \%$; na faixa de $15-19$ de $5,4 \%$ para $6,7 \%$ e na faixa de $20-24$ de $15,5 \%$ para $17,3 \%$, respectivamente (Fundação Seade: 1988 ).

8. Os índices mais altos de homicídio como causa de morte registrados em São Paulo correspondem aos grupos etários de 10 a 19 anos $(39 \%)$ e de 20 a 49 anos $(16,5 \%)$, especialmente nas

\section{BIBLIOGRAFIA}

BRASLAVSKY, Cecilia, Juventud y Sociedad en la Argentina, CEPAL, 1985.

FUNDAÇÃO SEADE, O Jovem na Grande São Paulo, São Paulo, Coleção Realidade Paulista,1988.

MADEIRA, Felicia, Os jovens $e$ as mudanças estruturais na década de 70: questionando pressupostos e sugerindo pistas, Cadernos de Pesquisa, FCC, São Paulo, N ${ }^{\circ}$ 58, Agosto, 1986.

MANNHEIM, Karl, Diagnostic of Our Time, Routledge \& Kegan Paul, Londres, 1954.
MARTINS, José de Souza (coord), O Massacre dos Inocentes, São Paulo, Hucitec, 1991. MELLO, Maria Cecilia Figueira, Segregação sócio-espacial na cidade de São Paulo e marginalização da criança $e$ do jovem, Cadernos de Pesquisa, FCC, São Paulo, $N^{\circ}$ 78, Agosto, 1991.

ROLNIK, Raquel, Kowarick, Lúcio, Somekh, Nadia (orgs), São Paulo: crise e mudança, SEMPLA, Brasiliense, São Paulo, 1990.

SPOSITO, Marilia Pontes, $O$ Migrante e a educação: o sonho nutre a luta, Travessia, Ano I, $\mathrm{N}^{\circ} 2$, dezembro, 1988. 